\title{
Using a Learner-Centered Approach to Teach ICT in Secondary Schools: An Exploratory Study
}

\author{
Said Hadjerrouit \\ University of Agder, Kristiansand, Norway
}

Said.Hadjerrouit@uia.no

\begin{abstract}
Despitethe importance of ICT (Information and Communication Technology) as a school subject in secondary education, there is a lack of an integrated ICT pedagogy that is elucidated within a broad framework of educational practice. The focus is still on technicalities and reproduction of knowledge rather than conceptual understanding of ICT. To realize the potential inherent in ICT, there is a need for innovative ICT pedagogies in secondary education. The purpose of this work is to involve student teachers in applying and evaluating a learner-centered ICT teaching method in their teaching practice at the secondary school level. The goal is to explore student teachers' learning processes when practicing the method and critical fact ors of success.
\end{abstract}

Keywords: Design-based research, digital literacy, ICT pedagogy, learner-centered ICT teaching, learning cycle

\section{Introduction}

The new national curriculum for schools in Norway from 2006 requires teachers to acquire a high degree of digital literacy in all subjects (Erstad, 2006; Krumsvik, 2006). However, in order to incorporate digital literacy in an effective way, there is a need for innovative pedagogical approaches to ICT. Traditional ICT teaching methods do not provide understanding of ICT on a deeper level than memorizing details of the soft ware, reproducing information about buttons, menu commands, and dialogue boxes (Herskin 2004; Sein, Bostrom, \& Olfman, 1998). Furthermore, despite the emphasis on ICT in secondary schools, ICT pedagogy is still in its infancy and there is a lack of essential computer skills among teachers, partly because, in contrast to mathematics, ICT as a school subject is a young discipline (Woollard, 2005). While there is a huge literat ure on the use of ICT as a tool in teaching and learning, there is much less published research work on the teaching of ICT as a school subject. As a result, there have been in the past and therepersist even now strong disagreements about the nat ure of ICT or similar designations, such as informatics or computer science, its aims, content, teaching and learning methods, and assessment approaches (Hammond, 2004). In line with international research in the field of school informatics (Dag-

Material published as part of this publication, either on-line or in print, is copyrighted by the Informing Science Institute. Permission to make digital or paper copy ofpart or all of these works for personal or classroomuse is granted without fee provided that the copies are not made or distributed for profit or commercial advantage AND that copies 1 ) bear this notice in full and 2) give the full citation on the first page. It is permissible to abstract these works solong as credit is given. To copy in all other cases or to republish or to post on a serveror to redistribute to lists requires specific permission and payment ofa fee. Contact Publisher@.InformingScience.org to request redistribution permission. dilelis, Satratzemi, \& Evangelidis, 2004;

McDougall \& Boyle, 2004; UNESCO, 2002; W at son, 2006; W oollard, 2005), this paper argues that innovative pedagogies based on contemporary learning theories can be a catalyst to incorporate digital literacy in an effective way. In line with the cognitive, constructivist, and situated learning theories, this paper presents a learner-centered ICT teaching method that is supposed to provide the 
students with a more thorough understanding of ICT as a school subject. To assess the pedagogical value of the method, it is intended to involve student teachers, having a university degree in informatics, in applying and evaluating the method in their teaching practice in upper secondary schools (the last three years of secondary education). Hence, the main objective of this work is to investigate the effectiveness of the ICT teaching method, and critical fact ors of success, through successive cycles of experiments based on the Design-based research paradigm (The DesignBased Research Collective; 2003).

\section{Research Methodology}

In this section the research methodology and associated research goals and questions are presented.

\section{Design-Based Research}

Design-based research is "an emerging paradigm forthe study of learning in context through the systematic design and study of instructional strat egies and tools" (The Design-Based Research Collective, 2003, p. 5). The purpose of Design-based research is to develop theories about the learning process and the pedagogical means that are designed to support that learning (Barab \& Squire, 2004). The essential characteristic of Design-based research is that it describes a continuous cycle, or feedback loop, of gradual refinement of the proposed theories. Refinements are continually made through successive cycles of experimentations, where the shortcomings of each cycle are identified, re-designed, re-implemented, and re-evaluated. Each cycle has four major phases: analysis, design, implementation, and evaluation. To better focus on the process as a research methodology, depending on information and producing results, two columns labeled inputs and outputs are shown in Figure 1. Inputs are influencing fact ors. Outputs are results of the process steps. Design-based research in ICT education involves four major phases:

1. It begins with the analysis of the learning problems of current educational practice in the field of ICT education. A critical literature review is conducted, thereby generat ing the formulation of hypotheses and research questions of interest.

2. It continues with the design of a learner-centered ICT teaching method, based on a theoretical framework, which will be used to overcome the learning problems. The framework supports the designers' work, forming the foundation for implementation and evaluation.

3. Then, an attempt at implementing learner-centered ICT teaching in secondary schools is performed, using multiple, both qualitative and quant it at ive, methods for collecting empirical data, e.g. survey questionnaires, interviews, observations, etc.

4. Finally, implementations of learner-centered ICT teaching are then evaluated. The evaluation is concerned with the systematic analysis of the dat a collected according to the specification implicit or explicit in the theoretical framework. 
In order to clarify the concept of digital literacy, it is important to understand the role of ICT in secondary schools. According to Webb (2002), three categories can be identified: learning ICT as a school subject (or school informatics), using ICT as a tool for leaming, and learning through ICT. ICT as a tool and learning through ICT are not considered in this paper.

ICT as a school subject in the new national curriculum is divided into Information T echnology I and II. Information Technology I includes four topics: Digital equipment, programming, multimedia applications, and Web development I. Information T echnology II includes three topics: Information systems design, databases, and Web development II. Teachers and students need to be familiar with these topics in order to acquire digital competency. More specifically, digital competency in the ICT subject involves the acquisition of a number of ICT skills. The first skill is concerned with using software tools, such as Excel, FrontPage, Photoshop, Access, and similar software for problem solving, simulation, modeling, exploration, visualization, and publication. The second skill is about using Internet for finding information, analyzing, processing, and presenting data with appropriate aids, and to be critical of sources, analyses, and results. Then teachers and students need to learn about Web design, development of interactive multi-media applications, connecting Web applications with databases, publishing and maintaining Web sites, as well as user-centered design, such as ease-of-use and ease-of-learning, subjective satisfaction, etc. Then, it is useful to acquire skills associated with software development approaches, both objectoriented and conventional methodologies, for analyzing problem situations, modeling, implementing, and testing appropriate solutions. Finally, programming with Java or similar languages is an important skill. Acquiring programming skills means analyzing the problem, breaking down the problem-solving process into its components, and designing an algorithm before coding.

However, despite the emphasis on a set of well-definedtopics, the new national curriculum makes few suggestions asto which pedagogical skills teachers need to acquire in order to teach these topics. In fact, the pedagogy of ICT is still in its infancy. It lacks an extensive research base of materials like the one published for mathematics. According to the research literat ure (Dagdilelis et al., 2004; Erstad, 2006; Hammond, 2004; Hennessy, Ruthven, \& Brindley, 2005; Krumsvik, 2006; Minaidi \& Hlapanis, 2005; Webb, 2002), ICT as a school subject is confronted with a number of closely related problems that are difficult to solve. First, schools adapt slowly to technological and pedagogical changes despite the fact that many attempts at implementing ICT have been initiated since 1980 in many countries. In addition, teachers are often reluct ant to abandon their existing pedagogy. As a result, teaching methods based on conventional epistemologies are still dominant despite the potentialities of innovative pedagogies based learning theories, such as constructivism and situated learning. Furthermore, teachers lack specifictraining and qualifications in ICT. A major problem for teachers is the complexity of software. While knowledge about the principles and functionality of soft ware is necessary for teaching ICT, it is impossible for teachers to know all the specific feat ures of all the soft ware packages that they use, because software is continually being developed and improved. Another important problem for teachers is identifying suitable context of software use to develop ICT knowledge and skills. These contexts may be taken from the school context, the wider community, e.g. private or public sector, or from another subject area. Moreover, teaching resources and textbooks in ICT are still based on traditional pedagogies. Textbook publishers have difficulties to incorporate innovative teaching approaches that are suited to ICT, mostly because they are driven by market ing forces rather than pedagogical considerations. Finally, a number of ICT topics are more difficult to teach than other subjects, because they require a much greater range of professional and pedagogical skills than those required to teach a unit of work within a specific subject area.

Given the current state of ICT education, there is a need for an integrated ICT teaching strategy that recognizes the interrelations of pedagogy, ICT skills, and school environment in order to suc- 
Hadjerrouit

cessfully exploit the potential capabilities of ICT in secondary education. To achieve this, schools must give more consideration to new pedagogies that are more suited to ICT.

\section{Learner-Centered ICT Pedagogy: Theoretical Framework}

The design of a learner-centered ICT teaching method depends on the chosen theoretical framework. The framework supports the designers' work, forming the foundation for implementation, evaluation, and research. The theoretical framework is developed in four steps:

1) Defining the psychological foundations of the learning-centered ICT teaching method based on learning theories and the learning cycle.

2) Specifying the underlying pedagogical principles of the leamer-centered ICT teaching method.

3) Re-conceptualizing pedagogical principles of the ICT teaching method within learning theories and the learning cycle.

4) Defining the contextual factors influencing the use of the learner-centered ICT teaching method in secondary schools.

\section{Psychological Foundations of ICT Teaching}

Important to the design of a learner-centered ICT teaching is a psychological foundation built on solid learning theory. Lit erat ure reviews sugge st that learning theories can be relat ed to three wi despread models: cognitivist, constructivist, and socially sit uated model of learning. The remainder of this section describes the most important characteristics of the learning theories and presents athree-stage model - the learning cycle - that retains the features of each one.

The cognitive learning theory emphasizes the learner's schema as an organized knowledge structure (Bruner, 1990; Gagne, Yekovich, \& Yekovisch, 1993). Unlike behaviorism, cognit ivism recognizes that the human mind is not simply a passive recipient of knowledge. Rather, the learner interprets knowledge and gives meaning to it. The cognitive perspect ive of learning refers to mental activity, such as analytical reasoning. When teachers apply a cognitive approach, they focus on the understanding of concepts and their relationships. If learners are able to understand the connections between the concepts, break down information, and rebuild it with logical connections, then their understanding will increase.

The constructivist learning theory views knowledge as a constructed ent ity made by each and every leamer through a leaming process. Constructivism frames learning less as the product of passive transmission than a process of active construction whereby the learners construct their own knowledge base d upon prior knowledge (Duffy, Lowyck, \& Jonassen, 1993; Piaget, 1971; Steffe \& Gale, 1995). Constructivist learning requires learners to demonstrate their skills by construct ing their own knowledge when solving real-world problems. The constructivist model calls for learner-centered instruction, because learners are assumed to learn better when they are forced to explore and discover things themselves.

The socially situated learning theory can be seen as a correction to constructivism, in which learning is disconnected from the social context. Whereas in the constructivist paradigm learning is assumed to occur as an individual learner interacts with study material, this perspective regards learning as socially situated and knowledge as socially distributed (Vygotsky, 1978; Wengler, 1998). Learning occurs as learners exercise, test, and improve their knowledge through discussion, dialogue, communication, collaboration, information sharing, and interaction with others. Vygotsky argued that the way learners construct knowledge, think, reason, and reflect on is 
uniquely shaped by their relationships with others. He argued that the guidance given by more capable others, allows the leamer to engage in levels of activity that could not be managed alone.

The literature on leaming theories points to the fundamental philosophical differences bet ween them (Lin \& Hsieh, 2001). However, in practice, a blend of learning theories is being used. Indeed, educators tend to believe that what works in a learning situation is a subtle combination of learning theories (Karagiorgi \& Symeou, 2005).

Along the same line of argument, Mayes and Fowler (1999) proposed a three-stage model or learning cycle, in which they identified three types of learning - conceptualization, construction, and dialogue. The essential characteristic of the learning cycle is that it describes a continuous cycle, or feedback loop, of gradual refinement of understanding. Accordingly, learning develops in three phases, beginning with conceptualization, progressing through construction to dialogue. Conceptualization is characterized by the process of interaction between the learners' pre-existing framework and teacher's knowledge. The construction phase refers to the process of building and combining concepts through their use in the performance of meaningful tasks. The dialogue phase refers to the testing of conceptualizations and the creation of new concepts during conversation with both fellow learners and teachers. Dialogue emerges through collaborative learning.

The three stages of the learning cycle include elements that are closely related to leaming theories. Conceptualization is associated with the cognitive learning theory as it focuses on concepts and their relationships. The construction phase is related to the constructivist leaming theory as it aims at the construction of new knowledge and its use in the performance of task-based activities. The dialogue phase is based on the socially situated learning theory as it is concerned with dialogue, group collaboration, and discussion.

\section{ICT Pedagogical Principles}

The ability to make use of soft ware tools for problem solving requires the acquisition of a number of ICT skills, e.g. remembering commandos and dialogue boxes, finding details associated with the software, understanding the soft ware functions and their relationships, understanding the overall principles of the software, finding the right sequence, creating associations in their own language, transferring previously acquired skills to the software, etc.

The following description of ICT pedagogical principles is based on an article published in 2007 (Brodahl, Fagernes, \& Hadjerrouit, 2007). According to Herskin (2004), teaching these skills involves two major steps. First, the teacher gives an overview and demonstrates the functionality of the software. Second, the students do hands-on exercises using the software. During the overview the teacher uses a video projector to present the software functions, and demonstrat es how the following exercise should be solved. Then, the students work on their own, trying to remember this procedure. There are three basic problems that are related to this form of teaching ICT:

1) The memory problem: The student must remember a detailed procedure.

2) The understanding problem: The student has not understood the principles of how to solve the exercise.

3) The dependence problem: The student is not able to work on his own solving the problem.

Techniques, such as teaching small groups, breaking down the lessons into smaller parts, providing the students with detailed manuals showing how the exercise should be solved step-by-step, using textbooks, or adopting similar methods, do not solve the basic problems of traditional ICT teaching. However, as Webb (2002) argued, it is important for teachers not be overwhelmed by trying to master all the details of soft ware but to focus on the main features of types of soft ware 
and how to find information about the detailed techniques. In line with this approach, Herskin (2004) proposes a teaching method relying on ICT pedagogical principles with three objectives:

- First, an important objective is to remove the details needed to be remembered, using a problem-oriented understanding process, and changing the focus from memorizing to understanding. For this purpose, the concept of instruction sheet is proposed.

- Second, for generating understanding, teachers use "understanding tools".

- Third, a pedagogical strategy is identified consisting of the single steps of the leaming process, and the problems associated with those.

As a result, the pedagogical strategy for teaching ICT has three major, but closely related phases:

a) Overview phase (or presentation phase)

b) Exercise phase (or hands-on phase)

c) Summary phase.

The objective of the overview phase is to generate understanding using "understanding tools". These could be situated examples, visualizing, and dialogues. By using situated examples, the teacher should enable the students to underst and the problem. The principles are then explained through visualizing. Finally, the teacher gives a procedure overview using visual boxes showing the main steps of the problem solving process. This is what Herskin (2004) calls the three P's. Accordingly, the overview phase has three components:

a) The Problem,

b) The Principles, and

c) The Procedural overview.

The fundamental idea behind the instruction sheet is to provide the student with a brief manual. The aim is to enable the student to become less dependent on the teacher's assistance. The instruction sheet should not contain any screen shots, but helps the student pay attention to information in menus and dialogue boxes of the software tool. Before the students do the exercise, an instruction sheet for this kind of exercise is handed out. The instruction sheet should give a generalized explanation on how to solve this kind of task. The exercise it self should only describe the problem, not specifying how to solve it. An important issue is not to mix the exercise and the instruction sheet. The instruction sheet is divided into three columns:

- Column 1 gives a procedural overview (heading: "PHASE")

- Column 2 explains why the student should perform this step (heading: "EXPLANATION"). This column could be left blank for the student to fill in

- Column 3 leads the student to the correct menu, buttons, dialogue boxes etc. (heading: "INT ERACT ION")

An instruction sheet for uploading files in the LMS Classfronter is illustrated in Table 1. 


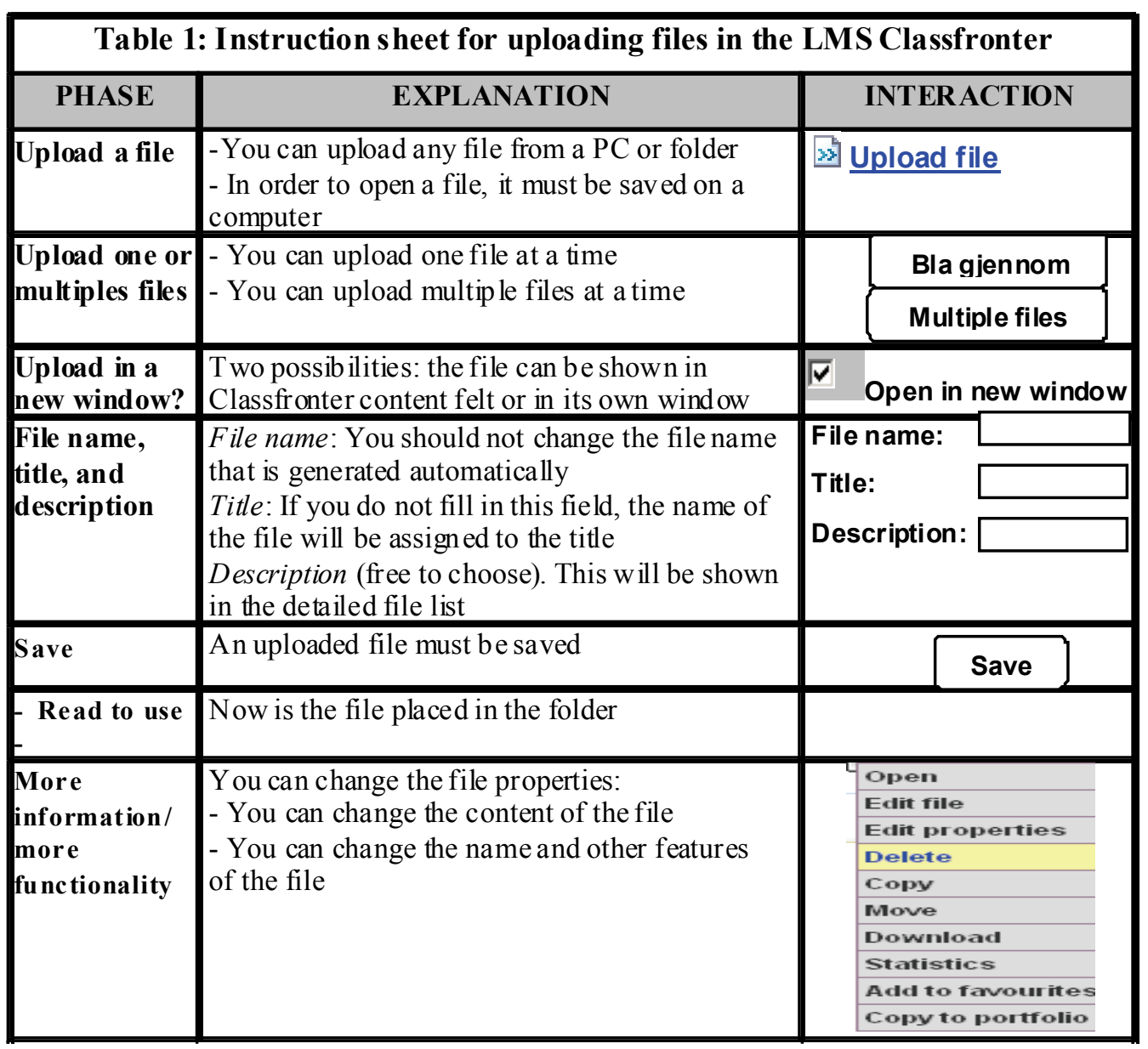

In the summary phase, students get the opport unity to raise questions regarding the specific exercise or more general problems. The teacher can provide supplementary information. In this phase the students might also discuss how the soft ware functions could be used in similar situations.

\section{Re-conceptualizing ICT Pedagogy within the Learning Cycle}

Herskin (2004) does not refer to leaming theory to support or justify his method, but the author of this work can draw a clear line from Herskin's pedagogy to leaming theories and the learning cycle (Brodahl et al., 2007).

First, Herskin describes learning processes in a way that support well-known cognitive learning theory. Instead of imitation or repetition, knowledge is acquired through involvement with content and realistic problem solving. In Herskin's model, students acquire an understanding of the software using understanding tools, among them situated examples for describing the problem, visualizations for explaining the principles, and procedure overview for showing the main steps of the problem solving process.

Second, in the exercise phase, knowledge is constructed through involvement with instruction sheets and realistic problem solving. The fundamental idea behind the concept of instruction sheet is to enable students to become less dependent on the teacher's assistance. The aim is to enable each student to work at his/her own pace, and from his/her prerequisites. The teacher works as a mentor of learning, not as a transmitter of knowledge. This fits in well with the constructivist learning theory. 
Third, in the summary phase, students get the opportunity to raise questions regarding the specific exercise or more general problems. Any learning by co-operating is donethrough teachermanaged dialogue in the student group. Hence, in the opinion of the author, there is a slightly lower degree of socially situated learning in Herskin's method. Hence, it can be useful to let the students work together in the exercise phase. This might mean less differentiating of the students, but will increase the learning by co-operating in a higher degree.

As a result, the three stages of Herskin's ICT pedagogy can be re-conceptualized within the learning cycle and associated learning theories. The overview phase is associat ed with the conceptualization phase of the learning cycle and the cognitive learning theory as it focuses on concepts and their relationships. This phase should last approximately 15-20 minutes. The exercise phase is related to the construction phase of the learning cycle and the constructivist learning theory as it aims at the construction of new knowledge and its use in the performance of task-based activities. This phase should last approximately 45 minutes. The summary phase is related to the dialogue phase of the learning cycle and the socially situated learning theory as it is concerned with dialogue, group collaboration, and discussion. This phase should last about 10-15 minutes.

In addition, at any stage of the ICT pedagogy there can be an emphasis on all the three stages of the learning cycle, depending on the situation: learning as cognition, learning as knowledge construction, and learning as dialogue and social practice. Hence, overview phase, exercise phase, and summary phase are not separated. They are interdependent and reciprocal. In addition, the essential characteristic of the ICT pedagogy is that it describes a continuous cycle, or feedback loop, of gradual refinement of understanding. Figure 2 gives an overview of the learner-centered ICT teaching method with respect to the re-conceptualization of the method within the learning cycle and learning theories.

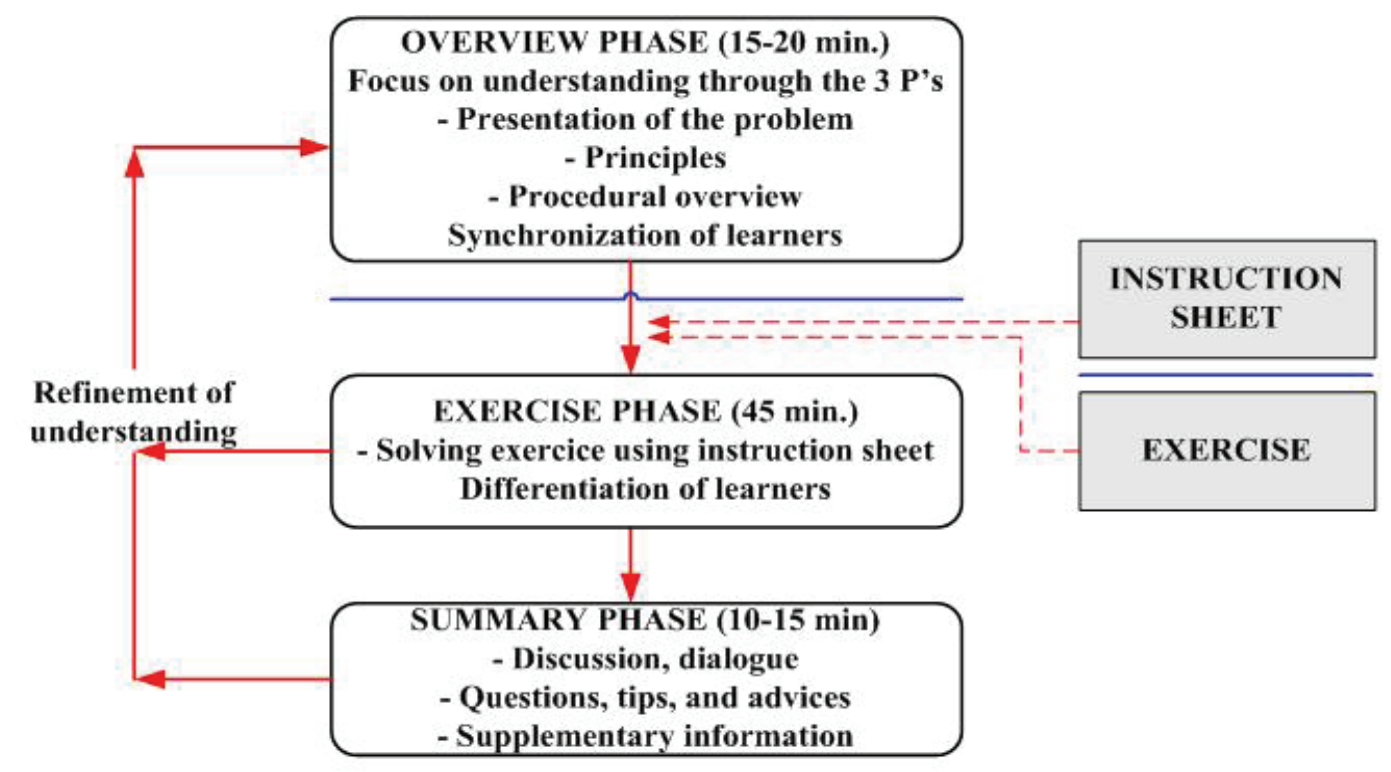

Figure 2: Learner-centered ICT teaching method as continuous cycle of gradual refinement 


\section{Factors Influencing ICT Teaching in Secondary Schools}

Secondary school classrooms are tightly regimented by a timetable and a number of factors that can constrain the experimental sessions with the ICT teaching method (Valcke, Rots, Verbecke \& Van Brak, 2007). These factors are related to a number of internal and external elements (Figure 3 ): Teacher education initiated by universities and performed by university teachers, the new national educational reform and digital literacy, schoolteachers' ICT and pedagogical knowledge, current school pedagogical practices, availability of ICT learning resources and study material; student teachers' ICT skills and pedagogical knowledge; pupils' ICT skills and knowledge; and assessment procedures used to evaluate ICT teaching.

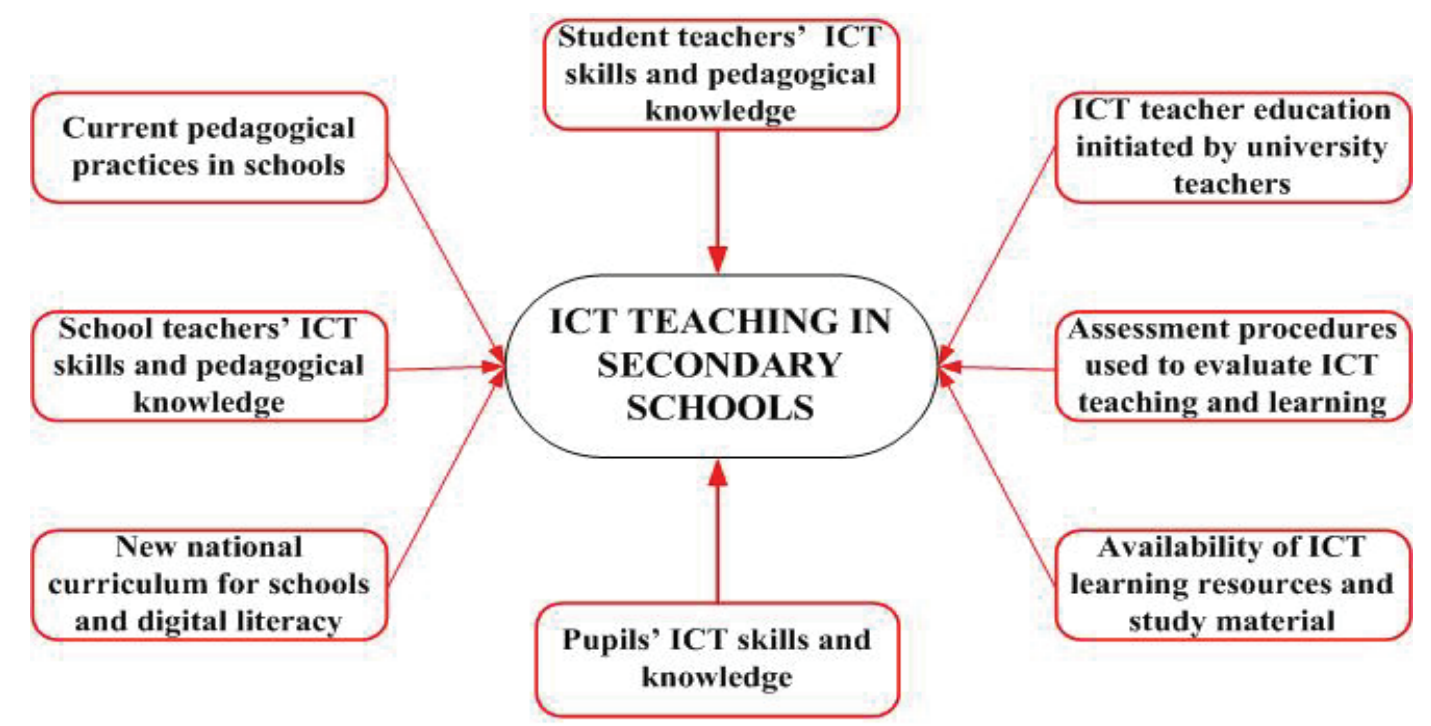

Figure 3: Factors influencing ICT teaching in secondary schools

\section{Evaluation Methods}

This study was situated within teacher education at the university level in collaboration with a number of secondary schools, where teaching practice of six weeks was performed. The unit of study was the learning of ICT as a school subject using a learner-centered ICT teaching method.

The goal of the study was twofold. Firstly, to analyze how student teachers, having a university degree in informatics, apply the learner-centered ICT teaching method in their teaching practice. Secondly, to identify critical factors of success, which require attention in fut ure experiments. An explorat ory approach based on the Design-based research paradigm was use d to explorethe students' application of the method. Accordingly, it may be necessary to continually refine the teaching method through successive cycles of experimentations, where the shortcomings of each cycle are identified, redesigned, re-implemented, and re-evaluated. As a result, two cycles of experimentations were performed, the first one in 2005 and the second one in 2006. Thus, evaluation findings are described with regard to:

- The first experiment with the ICT teaching method in the spring semester of 2005 and the redesign of the method according to the evaluation findings of the first experiment

- The second experiment with the ICT teaching method that was performed in the spring semester of 2006 
The qualitative paradigm (Bryman, 2004) was found to be suitable for evaluating the implementation of the ICT teaching method in upper secondary schools, mainly because the study focused on student teachers' learning processes, as well as final outcomes and personal aspects, such as student teachers' experiences, beliefs, thoughts, feelings, actions, and learning difficulties. Accordingly, to answer the research questions, particular attention was devoted to the following evaluation methods and their combination to a multi-strategy of data collection:

- Student teachers' feedback on their experiences with the ICT teaching method and formal discussions during the oral exam

- Informal discussions with the student teachers over a three-monthtime period

- Analysis and evaluation of student teachers' written project reports and associated educational materials that they produced at the end of the experiment

- Teacher's field notes and observations of student teachers' act ivities during their teaching practice in upper secondary schools

- Finding evidence drawn from the research literat ure that confirms or contradicts the data collected and the evaluation results

- Comparing the evaluation results of the first experiment from 2005 with those of the second experiment from 2006

Data analysis consisted of finding diverse pieces of evidence from diverse data sources: formal and informal discussions with the student teachers, analy sis of project reports, teacher's observations and field notes, literature research, and comparing the first with the second experiment.

\section{Evaluation of the First Experiment}

The learner-centered ICT teaching method was applied for the first time by student teachers in 2005. The application of the method was defined as compulsory research-based task for student teachers taking the course in Practical ICT Didactics. During their teaching practice, they had to apply the ICT teaching method. T eaching practice was of six weeks' duration, from the end of January until the beginning of March (Brodahl et al., 2007).

Prior to their teaching practice, the student teachers were presented to the ICT teaching method in lecture course of three hours' duration. In addition to this presentation, they had to study a textbook related to the ICT teaching method (Herskin, 2004), which was a part of the required course reading material.

At the end of their practice, the student teachers had to resume their experience in a project report of 60-80 pages. This report made $40 \%$ of their port folio, which was graded and presented in an oral exam. During this exam, they had to give feedback on their experiences of the ICT teaching method. Each student teacher was given this question during the oral exam: "What is the most important thing you have learned in the process of planning and teaching in accordance with the ICT teaching method?"

\section{Participants and Teaching Subjects}

There were 9 student teachers who participated in the experiment, 191 pupils between 16-18 years from 9 different schools, 11 school teachers as practice supervisors, and 2 university teachers as academic supervisors.

The context, in which the research-based tasks were carried out, is listed in Table 2. Each row refers to the student teacher's research-based task (teaching subject), number of lessons of $45 \mathrm{mi}$ - 
nutes, and number of participating pupils. The extent of the research-based tasks differed from student to student.

\begin{tabular}{|l|c|c|}
\hline \multicolumn{2}{|c|}{ Table 2: Student teachers' resea rch-based tasks in the spring semester of 2005 } \\
\hline \multicolumn{1}{|c|}{ TEACHING SUBJECTS } & DURATION & NUMBER OF PUPILS \\
\hline Creating forms and templates using Microsoft FrontPage & $2 \times 45 \mathrm{~min}$. & 18 \\
\hline Creating diagrams using Microsoft Excel & $3 \times 45 \mathrm{~min}$. & 36 \\
\hline $\begin{array}{l}\text { Connecting a database to a web site using Microsoft } \\
\text { Access and Microsoft FrontPage }\end{array}$ & $2 \times 45 \mathrm{~min}$. & 11 \\
\hline $\begin{array}{l}\text { Using hyperlinks and style sheets in Microsoft FrontPage } \\
\text { Creating hyperlin ks, changing backgrounds and font } \\
\text { colors in Microsoft FrontPage }\end{array}$ & $2 \times 45 \mathrm{~min}$. & 11 \\
\hline $\begin{array}{l}\text { Drawing graph s with the calculator simulating program } \\
\text { T-Interactive }\end{array}$ & $2 \times 45 \mathrm{~min}$. & 11 \\
\hline $\begin{array}{l}\text { Using scientific calculator (with advanced functions and } \\
\text { derivation) }\end{array}$ & $3 \times 45 \mathrm{~min}$. & 23 \\
\hline $\begin{array}{l}\text { Implementing the project management tool Microsoft } \\
\text { Project }\end{array}$ & $1 \times 45 \mathrm{~min}$. & 11 \\
\hline $\begin{array}{l}\text { Using basic functions in the photo imaging software } \\
\text { Adobe Photoshop 6.0 }\end{array}$ & $6 \times 45 \mathrm{~min}$. & \\
\hline
\end{tabular}

\section{Evaluation Findings}

The evaluation of the first experiment with the learner-centered ICT teaching method was published in a conference paper (Brodahl et al., 2007). The summary of the findings are described in the following sections.

\section{Student teachers' experiences on the basis of oral discussions}

To the question: "What is them ost important thing you have learned in the process of planning and teaching in accordance with the ICT teaching method?", st udent teachers responded differently in their formal discussions with theteacher in the oral exam.

All student teachers considered the method to be demanding and requiring considerable pre-work. Thinking they understood the method, working with it showed that they did not pick up important parts of the method. In addition, considering the instruction sheet as the method's main point, the students emphasized on elaborat ing this, failing to provide as much att ent ion to other important parts of the method. Finally, preparing lessons, the student teachers called attention to the lack of exemplary and approved study material. They asked for more examples, especially instruction sheets. Some of the student teachers' statements about how they considered the method to be used in schools were: "Themethod seems to be appropriate for adapted, differentiated teaching."; "The method is developed and might fit best for older, mature students. Itmight be modified to fit the pupil's age and level."; "The user may gain most from the method when using it for a longer period of time and becoming more fam iliar with it."; "The method might be more suitable for well-defined and less complex problem s." Moreover, student teachers reported that their pupils 
liked the strict and logical structure of the method and appreciated the method reducing the memory load.

\section{Analysis of student teachers' written project reports}

The analysis and evaluation of student teachers' reports showed the following results. Clearly, none of the students did implement the ICT teaching method in total compliance with its underlying principles, when applying it for the first time. Most of the student teachers had not been aware of their deviations; other knowingly made alternative choices, some of them in order to lighten their preparation work. As a result, they paid most attention to the hands-on phase (exercise) and considerably less to the overview and summary phase. They often integrated an exercise or parts of it into the instruction sheets. Doing so, they mixed up thetwo elements in the hands-on phase of the method, which, essentially, must be kept apart according the method's basic principle. In addition, some student teachers mixed up the instruction sheet with an example or with several smaller examples. Their instruction sheets adapted the three columns (phase, explanation, interaction), but their contents were similar to tutorials guiding the user through specific tasks. Finally, student teachers were critical about the fact that neither the academic supervisors (the university teachers), nor the practice supervisors (schoolteachers) could provide sufficient teaching resources and documented experiences, as it was the first time that this kind of project work was carried out. They believed that documented experiences with the learner-centered ICT teaching method would have helped them to better perform their project activities.

\section{Observations of student teachers' research activities}

The most important observations during the teaching practice were as follows. First, it turned out to be a problem for most student teachers to make room for trying out this kind of research in upper secondary schools. In most cases, the school timeframe had not been in line with the student teachers' six weeks practice and the need for trying out the ICT teaching method. Second, trying to function simultaneously both as researcher and teacher was quite challenging for all student teachers, in line with the research literature (Cochran-Smith, 2005). Third, the practice supervisors of student teachers, that is to say school teachers, did not have sufficient knowledge of the ICT teaching method. Therefore, they could not provide the student teachers with qualified supervision on planning and carrying out the teaching method. As a result, they did not encourage the student teachers' motivation. Furthermore, it has been observed that not all student teachers reorganized their teaching radically. Some of them went on with a demo-oriented teaching concept (demonstrat ing the program functions on the big screen), but tried to improve the teaching by adapt ing minor parts of the ICT teaching method. However, this cannot be considered as trying out the teaching method. Finally, even if all student teachers chose "light versions" of the method, some of them uncritically, they believed they had still acquired valuable experience, which enables them to change their teaching more radically in the fut ure.

\section{Redesigning the ICT Teaching Method after the First Experiment}

The first experience with the ICT teaching method enabled teacher students to suggest some changes in orderto successfully apply the method in upper secondary schools. The method was redesigned on the basis of student teachers' recommendations, on the one hand, and evaluation findings, on the other hand. As a result, the following modifications and corrections were considered to be important to the next experiment with the ICT teaching method.

First, a critical fact or of trying out the ICT teaching method in secondary schools is the understanding of the school environment, where the method is being used, and the associated factors influencing its application. These could play an import ant role in applying the method in schools. With respect to the student teachers' experiences, the influencing fact ors were: school teachers' 
ICT skills and pedagogical knowledge, pupils' ICT skills, the degree of implementation of ICT in schools, school timeframe, learning assessment, teaching resources, and the type of software used in the classroom. All these fact ors were mentioned in one or another form by the student teachers.

Second, it is important that student teachers follow the ICT teaching method entirely from the overview to the summary phase. The overview phase is important, because it provides the very basis of the ICT teaching process. In addition, the method should particularly emphasize collaboration in the exercise phase and dialogue in the summary phase. Collaboration and dialogue are import ant pedagogical tools in school education, since learning occurs as learners exercise, test, and improve their knowledge through discussion, dialogue, information sharing, and collaboration with fellow learners and teachers. Hence, it would be beneficial that some tasks are undertaken by groups of pupils working in teams, as collaborative skills are highly valued attributes in school education (McDougall \& Boyle, 2004).

Third, the application of the ICT teaching method should be formulated as a cont inuous cycle of gradual refinement of understanding with three stages of learning: learning as cognition, as knowledge construction, and as dialogue. It is important to continuously apply the method during the teaching practice. A continuous application, over a longer period of time, might be necessary to refine the pupils' understanding of software principles, which is an important factor of success.

Fourth, student teachers' preparation and pre-work at the university level - before entering the field of teaching practice - is an important fact or of success. Student teachers believed that prework should involve more than the theoretical understanding of the method's underlying principles. Therefore, it should not be limited to mastering concepts, but rather learning to use them to solve a variety of realistic ICT problems. This includes the ability to understand the underlying concepts, and to be able to apply them to solve ICT -based tasks using a variety of soft ware tools, before entering the field of teaching practice.

Finally, in addition to pre-work and preparation, student teachers reported that the lack of practical teaching material prevented them from applying the method as originally anticipated. Hence, teaching material and documented experiences must be available to the student teachers in order to provide support both to the preparation phase and the application of the method in theirteaching practice. Appropriate teaching material can be student teachers' project reports from past versions of the Practical ICT Didactics course, including well-designed instruction sheets, visual examples that can be reused with slight modifications, and motivating exercises. Study material must be made available online so that it can be accessed at any time and from any place.

\section{Evaluation of the Second Experiment}

Aiming at evaluating the applicability of the learner-centered ICT teaching method for the second time in upper secondary schools after the redesign of its underlying principles, the author intended to repeat the experimentation from 2005 under similar conditions as a compulsory research-based task for student teacherstaking the course in Practical ICT Didactics.

Prior to their teaching practice, the student teachers were presented to the method in two lectures of 4 hours' duration. In addition to lectures, they had to study a textbook and some study material related to the ICT teaching method (Herskin, 2004). Moreover, in order to prepare and motivate the student teachers to perform their project work, the teacher reported on previous experiences and project reports from the spring semester of 2005. Student teachers had to study the reports carefully, understand the examples, instruction sheets, and exercises, as well as the whole process of applying the ICT teaching method in all its phases. 


\section{Participants and Teaching Subjects}

There were 3 student teachers who participated in the experiment, 50 pupils between 16-18 years from 3 different schools, 3 school teachers as practice supervisors, and one university teacher as academic supervisor.

The context, in which the research-based tasks were carried out in the spring semester of 2006, is listed in Table 3. Each row refers to the student teacher's research-based task (teaching subjects), number of lessons of 45 minutes, and number of participating pupils. The ext ent of the researchbased tasks differed from student teacher to student teacher.

\begin{tabular}{||l|c|c|}
\hline \multicolumn{2}{|c|}{ Table 3: Student teachers' research-b ased tas ks in the sp ring semester of 2006 } \\
\hline \multicolumn{1}{|c|}{ TEACHING SUBJECTS } & DURATION & NUMBER OF PUP ILS \\
\hline $\begin{array}{l}\text { Creating i mages using the Web editor Micro soft } \\
\text { FrontPage }\end{array}$ & $2 \times 45 \mathrm{~min}$. & 17 \\
\hline $\begin{array}{l}\text { Using the LMS Classfronter for downloading files, } \\
\text { creating folders, keeping track of appointments in } \\
\text { Calendar, and changing preferences }\end{array}$ & $4 \times 45 \mathrm{~min}$. & 15 \\
\hline \hline $\begin{array}{l}\text { Connecting forms using the database pro gram } \\
\text { Microsoft Access }\end{array}$ & $3 \times 45 \mathrm{~min}$. & 18 \\
\hline
\end{tabular}

\section{Evaluation Findings}

To evaluate the application of the learner-centered ICT teaching method for the second time, the same evaluation methods, with some modifications, were used as in the first experiment in 2005.

\section{Student teachers' experiences on the basis of formal discussions}

During the oral exam, the student teachers had to give feedback on their experiences and their understanding of the ICT teaching method. Each student was given the following questions:

- "How did you use the ICT teaching method? Did you use it in accordance with its principles?"

- "What is the pedagogical value of the learner-centered ICT teaching method compared to traditional methods? What are the pedagogical insights you have gained in the process of planning and teaching in accordance with the method?"

- "Do you think that the ICT teaching method is appropriate for differentiated ICT teaching in upper secondary schools? "Do you think that the method is suitable for ICT teaching at the secondary school level?"

Hence, evaluation results are described with regard to the following issues:

1. Application of the ICT teaching method in accordance with its basic principles

2. Pedagogical value of the ICT teaching method in upper secondary schools

3. Suitability of the ICT teaching method in upper secondary schools

\section{Application of the learner-centered ict teaching method}

Prior to the application of the ICT teaching method, two student teachers reported that they entered project work with varied grad of motivation, either because of intrinsic factors likethe desire to study, progress and develop, seeing the method as a challenge, and wanting to participate 
in trying innovative ICT teaching methods. The third student teacher reported that she was not interested in the project idea, mostly because she wanted to choose her own project work. But, after some lectures and discussions with the academic supervisor, they found that the method was nevertheless interesting and worth exploring during their teaching practice. When it became evident that the student teachers' motivation at the beginning was relatively high, it became necessary to ensure that this did not decline during their teaching practice. Student teachers were expected to acquire sufficient experience in the method within six weeks with respect to the timeframe required for teaching practice.

The following conclusions can be drawn from the application ofthe ICT teaching method.

First, all student teachers followed the method's main components: presentation phase (with the three P's), exercise phase, and dialogue phase. In addition, they did not mix the exercise and the instruction sheet according to the method and its principles. Finally, they reported that the planning was different compared to traditional ICT teaching as it focused on conceptual understanding and leaming processes rather than the learning product.

Second, all student teachers found that the method was a challenge as the planning of teaching sessions required a lot of time and effort. All student teachers agreed that the ICT method was more demanding in terms of conceptual efforts than conventional teaching methods. In addition, they reported that the timeframe for applying the method was short forthis kind of work.

Third, when asked about what they considered as the most important aspect of the method, two students reported that they liked the method, because it gave them a holistic picture of ICT teaching, in particular the three P's (Problem, Procedure, and Principles). They felt that the first phase of the method was quite important to their pupils. In addition, they reported that well-designed instruction sheets contributed to the understanding of soft ware principles. But the design of instruction sheets was very demanding in terms of conceptual efforts. Finally, they reported that the summary phase did not play an important role as originally anticipated.

\section{Pedagogical value of learner-centered ICT teaching}

From a pedagogical point of view, two student teachers agreed that the learner-centered ICT teaching method is better suited to ICT than conventional teaching approaches, e.g. demonstrations, tutorials, group work, and traditional hands-on. They argued that the ICT teaching method combines a number of learning theories and pedagogical strat egies to an approach that takes into consideration the pupils' needs, problems, and difficulties. They believed that the teaching method is a pedagogical innovation as it provides a conceptual framework for understanding fundamental principles of software, in particular the first phase of the method, which provides a holistic understanding of soft ware. The third student teacher was rather skeptical from the very beginning concerning some component of the method. She agreed that the understanding of principles is quite important, but she did not believe that theteaching method is a pedagogical innovation as it does not differentiate enough. She did not agree that the method takes into consideration pupils' specific needs and learning styles. She thinks that ICT teaching at the upper secondary school level must use a variety of methods in order to meet the pupils' needs.

\section{Suitability of learner-centered ICT teaching in upper secondary schools}

All student teachers agreed that the method might be appropriate in upper secondary schools under some conditions. First, it is important that pupils possess some computer skills. Second, the method must be adapted to the pupils' needs, goals, and motivations. Third, the method requires pupils' self-confidence and maturity as the use of instruction sheets is demanding interms of 
conceptual and intellectual efforts. Fourth, it is important to let pupils help each other during the exercise phase instead of being dependent on the teacher's assistance.

Two student teachers were willing to use the method in all its dimensions in fut ure courses in upper secondary schools. The third one picked up some elements of the method, especially the understanding of software principles and the use of understanding tools, in order to combine them with other teaching methods and techniques.

\section{Analysis of student teachers' written project reports}

Project work evaluation during the second experiment was embedded in the learning process and spread out over the duration of the spring semester of 2006. The analysis and evaluation consisted of assessing the quality of the submitted project reports and the presentation of the results to the whole classroom. Feedback and comments from the academic supervisor gave student teachers the necessary pieces of how to perform project work. Student teachers benefited from reflecting on how they had achieved the learning goals, before they submitted their reports.

During the entire project work student teachers were communicating and discussing the results of their efforts with the academic supervisor and fellow student teachers. To formally communicate their results, they presented their work at the end of the course, showing what they had done and discussing what they leamed. The project report made $50 \%$ of their port folio, which was graded and presented in the classroom and during the oral exam.

The goal of the evaluation of the project reports was to find out whether the student teachers were able to apply the ICT teaching method in compliance with its basic principles and phases.

\section{Presentation phase:}

Basically, all student teachers reported that this phase was the most important part of the ICT teaching method, because it helped them to lay the groundwork for teaching fundamental principles of soft ware through the $3 \mathrm{P}$ 's and understanding tools, such as sit uated examples and visualizations, without the need of remembering all details of the software. However, they experienced that the preparation and planning of the present at ion phase was time consuming and very demanding in terms of efforts. Finding relevant situation examples, presenting a procedural overview, and using understanding tools for explaining soft ware principles, were challenging tasks and required more conceptual efforts than traditional ICT teaching.

\section{Exercise phase:}

Two student teachers reported that the exercise phase was very important from a constructivist point of view, because it required active involvement in authentic problem solving, such as building user-friendly data models using Microsoft Access, formatt ing pictures and integrating them into soft ware, writing common documents. In addition, the development of exercises was relatively easy for the student teachers, partly because specifying adequate exercises relied on work done during the presentation phase of the teaching method.

\section{Instruction sheet:}

From the project reports, it appears that all student teachers divided the instruction sheet in three columns. They filled in the instruction sheets with textual information, but they ignored to keep blank the instruction sheets' column for explanation in order to write down the navigation threads and keystrokes. They did not mix the instruction sheet with the exercise. In addition, one student teacher developed six well-structured instruction sheets that provided help for solving exercises associated with the LMS Classfronter. This is clearly a progress compared to previous experiences with the method. Two student teachers experienced that the design of well-structured instruction sheets required conceptual efforts as it was not easy to find an appropriate balance between information that is supposed to explain how the pupil should perform the steps specified in the procedural overview, on the one hand, and the menus, buttons, and dialogue boxes, on the 
other hand. The third student teacher did not encounter any obstacles when designing the instruction sheet. Finally, all student teachers agreed that instruction sheets are subject for reuse and adaptation for similar software problems.

\section{Summary phase:}

Due to the efforts invested in the present at ion phase and the difficulties encountered when designing instruction sheets, the summary phase suffered from the short timeframe remaining for this activity, result ing in very short dialogue. As a result, two student teachers did not pay much attention to the dialogue phase. One of them reported that the summary phase was not necessary, because the presentation phase provided sufficient support for understanding soft ware principles so that it was not important to the pupils to ask more questions. The third student teacher was relatively satisfied with the discussion that took place after the exercise phase, even if it was quite short.

\section{Evaluation ofpupils' learning with standard questionnaires:}

Pupils' learning was evaluated using standard questionnaires at the end the teaching sessions. The results can be summarized as follows.

Pupils, who used Microsoft Access, liked the ICT teaching method and the associated instruction sheets, because they gave them a generalized explanation of how to do the exercise without relying on much information and memorizing. Most of them possessed sufficient knowledge in Microsoft Access in order to understand the method. Some of the pupils' statements about the ICT teaching method were: "It helps for understanding. I used what I knew before and the new teaching method: "It was fine"; "I liked using many similar examples"; "Yes, it was very helpful using the instruction sheet you handed out"; "Instruction sheets are useful as they give you a procedural overview of what you need to do. It is impossible to do mistakes".

Most pupils, who used FrontPage, indicated that the ICT teaching method provided more support than FrontPage textbooks. They liked the presentation phase as it helped them to understand software principles through the $3 \mathrm{P}$ 'er and understanding tools, in particular visualizations. All pupils liked that the student teacher emphasized understanding rather than remembering technical details of the software, which is clearly one the most important feat ures of the teaching method. Yet, seven pupils did not use the instruction sheets as expected, sometimes ignoring them completely. Instead they asked their follow pupils for help. Nevertheless, more than the majority of the pupils believed that the instruction sheets were helpful. Unfortunately, the summary phase was given insufficient consideration. At the end, however, most pupils were globally satisfied with the ICT teaching method. They found that software principles were easier to understand when the student teacher used the ICT teaching method.

Finally, most pupils, who used the LMS Classfronter, had different attitudes to the ICT teaching method. Some were enthusiastic, while other did not like the teaching method. They reported that the presentation phase had two different learning effects depending on the degree of complexity of the soft ware functions. While most pupils did not encounter serious difficulties for understanding the most important and easy-to-use soft ware functions, they had problems with the more advanced LMS functions. Furthermore, pupils reported that they learned a lot in the exercise phase, but they did not use the instruction sheets as originally anticipated. Some of them did not understand them and how to use them. This was quite frustrat ing for the student teacher who invested a lot of time for designing six well-structured instruction sheets in the hope that her pupils will use them adequately. Finally, neither the student teacher nor the pupils gave sufficient consideration to the summary phase, resulting in few questions. 


\section{Observations of student teachers' research activities}

In contrast to the first experiment, it has been observed that it was easier to make room for trying out the ICT teaching method in upper secondary schools. In the schools where the second experiments were performed, it appeared that two school teachers were more prepared for letting the student teachers apply the method, even if they did not have sufficient knowledge in order to provide the student teachers with qualified supervision on planning and carrying out the learnercentered ICT teaching method. Nevertheless, they provided motivation and took into consideration some of the student teachers' concerns about timetable, number of lessons, pedagogy, and knowledge background. In contrast, the third school teacher did not appreciate the ICT teaching method, probably because he was not aware of the pedagogical potentialities of the method.

Moreover, it has been observed that student teachers used documented experiences that were available in form of project reports from the first experiment, which could be reused with some modifications, in particular instruction sheets, situated examples and exercises, as well as visualizations of soft ware principles. This made the application of the ICT teaching method easier compared to the first experiment. Furthermore, it has been observed that all student teachers reorganized their teaching according to the basic principles of the method, even if the summary phase was given insufficient consideration.

Finally, an important observation was that student teachers' knowledge background in informatics and prior pedagogical experience were important factors of success. This was the case of all student teachers, who clearly demonstrated theirteaching skills when applying the learnercentered ICT teaching method.

\section{Discussion}

In this section, a summary of findings and implications for the ICT teaching method in upper secondary schools are presented. The limitations of the study and recommendations for fut ure research work and experiments are discussed as well.

The findings help to answer the two research questions:

1. How do student teachers, having a university degree in informatics, apply and evaluate the learner-centered ICT teaching method in their teaching practice?

2. What are the critical factors of success in trying out the learner-centered ICT teaching method in upper secondary schools?

\section{Summary of Findings}

The student teachers' experiences with the ICT teaching method in two cycles of experiments can be summarized as follows:

a) The first experiment with the learner-centered ICT teaching method was not successful as originally anticipated. The method was new to all student teachers and, as a result, they struggled for applying it consistently according to its principles.

b) The second experience was more successful fortwo reasons. First, student teachers' confidence, motivation, and knowledge background both in ICT and pedagogy played an important role. Another key factor was the availability of learning resources. This does not mean that student teachers did not encounter difficulties, but these did not prevent them from trying out the method more consistently than those of the first experiment. 
c) Student teachers, who took part in the second experiment, displayed a higher level of satisfaction than those of the first experiment, especially with regard to the presentation and exercise phases as these positively influenced the understanding of soft ware principles.

d) Yet, a majority of the student teachers did not attach much importance to the summary phase. Instead, they showed a more pragmatic approach to communication with pupils as dialogue and discussion were spread out over the duration of the teaching sessions.

e) The planning of the ICT teaching method was demanding in terms of efforts and time for all participating student teachers, as it was not always easy to find intrinsically motivat ing examples and exercises for explaining software principles. Another problem was that it was not always possible to let pupils work independently without interfering and stimulating them to take part in discussion in order to ask the right questions.

f) Teaching material and learning resources were very important, in particular student teachers' project reports from previous versions of the course. The resources from the first experiment provided support for trying out the ICT teaching method for the second time, in particular with regard to the reuse of teaching material, e.g. instruction sheets, visual examples, and well-designed exercises.

g) Student teachers generally believed that the ICT teaching method has the potential for improving pupils' digital competency if it is applied consistently and continually, over a certain period oftime, and some (both internal and external) conditions are fulfilled.

\section{Implications for ICT Teaching in Upper Secondary Schools}

Having applied the leamer-centered ICT teaching method in two successive cycles of experiments in upper secondary schools, it is now possible to discuss the second research question, that is to say the critical factors of success in trying out the method in future cycles of experiments.

From a theoretical point of view, the ICT teaching method presented in this paper has great potential for transforming ICT pedagogies. It could have positive impacts on pupils' learning if secondary schools realize that the method offers affordances, which can transform existing pedagogical practices and push ahead with innovative ICT pedagogies (Pearson \& Naylor, 2006).

From a practical point view, however, the production of novelty, which is pedagogically and conceptually possible in the learner-centered ICT teaching method, may be inhibited when it is introduced into educational settings where traditional views of teaching are actually predominant. In fact, secondary school classrooms, including student teachers' involvement with ICT teaching, are tight ly regimented by atimetable and a number of external fact ors that can act as inherent barriers to change (Deaney, Ruthven, \& Hennassy, 2003; Hennessy et al., 2005). Similarly, internal factors can act as inherent barriers that prevent student teachers from trying out the ICT teaching method. These factors include student teachers' lack of confidence, pedagogical experience, and motivation, as well as the degree of software complexity and pre-existing classroom pedagogical practice. As a result, the integration of innovative ICT pedagogies into secondary education is a complex task. It can only succeed if a number of internal and external conditions are fulfilled simultaneously (Plomp, Pelgrum, \& Law, 2007).

Given this background, two elements are important to successfully apply the learner-centered ICT teaching method in upper secondary schools. First, the method should actively involve the stakeholders in the process of experimentation (Hayes, 2007), e.g. student teachers, school teachers, university teachers, and pupils. Second, the method should take into account pedagogical factors, such as assessment procedures, learning theories and approaches, learning resources, as well as curricular issues and the concept of digital literacy. From these considerations, several implica- 
tions for the implementation of the ICT teaching method are suggested. These are discussed in the next sections.

\section{Student teachers and teaching practice}

Radical pedagogical changes are clearly difficult to achieve in theirteaching practice of six weeks, mainly because, besides external and internal factors that can act as barriers that prevent student teachers fromtrying out new ICT pedagogies, working simultaneously as teacher (using an innovative ICT teaching method) and researcher (performing project work), are challenging issues for many student teachers to deal with in the classroom (Cochran-Smith, 2005; Postholm, 2006). Nevertheless, pedagogical changes are possible if the following conditions are fulfilled. First, to successfully apply the learner-centered ICT teaching method, student teachers must be motivated and convinced of the need for pedagogical change in ICT teaching and how change can be incorporated into their teaching practice. Second, it is an advantage that student teachers have solid background in ICT and sufficient pedagogical knowledge in order to be able to try out new ICT teaching methods. Third, student teachers should develop their ICT teaching in a way that motivates pupils and enriches learning or stimulate high-levelthinking and reasoning. Hence, with respect to the ICT teaching method's basic principles, student teachers' goals must be fostering pupils' independence, autonomy and ownership, as well as alleviating difficulties encountered in using software tools. Fourth, the way to teach ICT is of paramount importance to the learning process, because, according to Cox \& Marschall (2007), the instructional strategies ofteachers have been shown to have a significant impact on students' learning of ICT. Thus, one of the goals of teacher education is helping student teachers to critically discuss their teaching practice, since the way they were taught relate strongly to the ways they later teach (Barak, 2006). Finally, to deal with the challenges, student teachers must be in a position to negotiate timetable, pedagogical, and organizational barriers with school teachers, otherwise innovative ICT pedagogies cannot have the desire effect. Unfortunately, this was not always the case, especially during the first experiment.

\section{School teachers and school context}

School teachers, as practice supervisors, can be facilitators, inhibit ors of pedagogical change or conservat ors of the stat us quo of pedagogical practice in classrooms (Wat son, 2006). According to Nordkvelle and Olsen (2005), the problem of ICT in schools is often attributed to deficiencies of practice, for a number of reasons. First, schools are considered as conservative social structures that resist the challenges to redefine their teaching practice when integrating pedagogical innovations using ICT. Clearly, schools are slow adapters to change (Hayes 2007; Krumsvik, 2006).

Second, schoolteachers' attitudes, concerns, and beliefs affect the implementation of pedagogical innovations in ways that are consistent with instructional practices at their schools (Niederhauser $\&$ Stoddart, 2001). Hence, school teachers are often reluctant to abandon their exist ing pedagogy (Hennessy et al., 2005) and, as a result, they could inhibit or even hinder the implementation of pedagogical novelty that teacher students try to implement. According to Nordkvelle and Olsen (2005), changing schoolteachers' att it udes to pedagogical innovations, requires discussing the nat ure of the difficulties they face with ICT, and how they can deal with them and enhance practice. Clearly, they must be convinced that ICT is an educationally valuable tool. Hence, a factor of success is the consideration of schoolteachers' concerns and values when introducing new teaching methods. This means that innovative ICT teaching methods and pedagogies should be introduced gradually in accordance with the school teachers' concerns in order to avoid tensions between the actual pedagogical practice and pressure for pedagogical changes. This because mapping ICT innovative pedagogies onto classroom teaching is not a straightforward task, following a clear procedure. Clearly, factors of success depend on the specific school educational 
policy or even at the level of the individual school teacher. Hence, school teachers should not be forced to implement new ICT teaching methods no matter what the reasons are.

\section{Pupils and their needs}

Pupils' digital literacy is another important fact or that could promote or inhibit the potentialities of innovative ICT pedagogies, even in Norway, which has relatively little digital divide and a high information technology density (Krumsvik, 2006). It has been observed that pupils with insufficient digital competency do not use instruction sheets as required by the teacher student. $\mathrm{Pu}$ pils were not able to work on their own solving software problems using instruction sheets. Some became completely dependent on the teacher's help. However, while some knowledge background in computing is necessary, it is not sufficient for learning to use instruction sheets in order to become less dependent on teacher's help. Pupils' needs, self-confidence, motivation, and maturity are equally important factors of success. Clearly, the learner-centered ICT teaching method is not recommended in lower secondary schools due to the low level of pupils' digital competency and lack of maturity in managing their own learning process. On the other hand, it can be useful to let pupils work together in the exercise phase. This might mean less teacher's dependence, but more learning by collaboration with fellow pupils. But, as Jedoskog and Nissen (2004) stated, there is a risk to hand over much responsibility to the pupils themselves, because the process of transferring responsibility to the pupils can end in a situation where technicalities of the software receive more attention than conceptual understanding of soft ware principles.

\section{University teachers and teacher education}

One of the goals of teacher education at the university level is to promote the implementation of pedagogical novelty in the field of ICT education in secondary schools. To promote innovative ICT teaching methods, university teachers must not only be confident in their ability to try them out in their classes, but also to adapt them to the needs, learning styles, and prerequisite knowledge of their student teachers, as well as the school environment (Bit an-Friedlander, Dreyfus, \& Milgrom, 2004). Clearly, unless innovative ICT teaching methods are given sufficient attention at the university level, the implementation of new ICT pedagogies in upper secondary schools cannot develop fully. Hence, it is important that student teachers progress beyond the novice stage to higher-order skill levels in using the learner-centered ICT teaching method, and thus, acquiring mastery, at least at the conceptual level, before trying it out in schools. Furthermore, university teachers as academic supervisors must prepare their student teachers, because pre-work is an important factor of success. Preparing student teachers to apply innovative ICT teaching methods involves more than the theoretical understanding of soft ware principles. Therefore, student teachers' pre-work at the university level should not be limited to mastering concepts, but rather learning to use them to solve a variety of realistic ICT problems before entering the field of teaching practice. Finally, an important challenge for teacher education is to find new ways of creating opport unities for learning about teaching ICT (and teaching about ICT teaching) with student teachers. However, according to Loughran and Berry (2005), this is not a simple task, but such work is crucial to an articulation of ICT pedagogy.

\section{ICT pedagogy and learning theories}

ICT educators generally agree that there is a need for innovative pedagogical approaches based on learning theories (Dagdilelis et al., 2004; McDougall \& Boyle, 2004). They argue that progress in ICT teaching will only come from a better understanding of the learning process and the re-conceptualization of ICT education within cognitive, constructivist, and socially situated leaming theories. The alignment of the ICT teaching method presented in this paper with contemporary leaming theories is, therefore, an important goal of teacher education. In line with the cognitive learning theory and student teachers' experiences, the presentation phase of the ICT teaching 
method provides an adequate support to understand software principles. Likewise, the exercise phase of the ICT teaching method provides sufficient support for the knowledge construction process in compliance with the constructivist learning theory. However, the summary phase was less integrated into the method. Indeed, the data collected indicated that discussion and dialogue did not play a key role in teaching ICT, since neither student teachers nor their pupils did view the lack of discussion as a significant problem to the learning process, even if, from a theoretical point of view, the summary phase is important to consolidate the pupils' understanding of software principles. Hence, it can be useful to integrate the summary phase into the learning process in order to promote situated and collaborative learning. The question is how to do in an effective way. Which motivational strategies are needed to engage pupils in discussions? How to improve dialogue between teacher students and their pupils? These questions need to be addressed if the ICT teaching method has to achieve its promises of providing dialogues that support effective learning.

\section{ICT teaching material and learning resources}

The diffusion of ICT pedagogical innovations is dependent on suitable textbooks, teaching material and learning resources, which adequately address the underlying methods, principles, concepts, and ideas. However, theoretical study material and textbooks in themselves are not sufficient to provide practical experience and skill development when trying out an innovative ICT teaching method that is based on contemporary learning theories (Hsu, 2004). Teaching material developed by textbook publishers does not have a sufficient degree of flexibility. T eachers need to change the material (examples, problems, background information) to make it more flexible (Volman, 2005). In addition, existing textbooks do not cover fundamental concepts and fail to address the connections between the concepts using analogy, by transferring concepts from the known to the unknown, that is to say to new situations (Wu, Lee, \& Lai, 2004). The lack of descriptions on the relationship between concepts prevents teachers from understanding soft ware tools as a whole. To compensate the lack of practical learning material, it is of crucial importance to provide learning material and documented experiences from previous project reports that student teachers may explore and study, and eventually reuse with some modifications. Student teachers' project reports can be reused to extract teaching material, which can be used in the presentation phase to describe the problems, principles, and procedural overview of the subject matter using situated examples and visualizations. Previous study material can also be reused in the exercise phase to make problem solving more motivating and interesting for pupils.

\section{Formative asse ssment and cycles of experiments}

There are many ways of assessing the pedagogical value and the learning effects of the ICT teaching method: observations of pupils' learning; analysis of pupils' problem solving, formal and informal discussions with the pupils, standard questionnaires, etc. The question is how to do it in an effective way. Clearly, summative assessment based on quantitative evaluation, such as standard questionnaires, alone is not sufficient to assess the learning effects of the method in the long term. The method will be appropriately evaluated only if pupils are assessed formatively (Beverly \& Bronwen, 2002). Formative assessment occurs when student teachers feed information back to pupils in ways that enable them to learn better, or when pupils can engage in a similar, self-reflective process. Formative assessment is asking questions in order to determine the pupils' current understanding, so that student teachers can make adjustments if necessary. Formative assessment is based on the principle that the evaluation of learning should not be separated from the learning process. To be effective, formative assessment must be integrated into the ICT teaching method in order to generate some evidence-based data about the pupils' learning process. This requires that student teachers consistently use the ICT teaching method during their teaching practice. This kind of assessment is, however, difficult for student teachers to achieve, 
unless they function simultaneously both as teacher and researcher of their own teaching, which is a quite challenging task (Cochran-Smith, 2005).

\section{Software principles and ICT concepts}

Another fact or that may facilitate or inhibit the learning process is the type and the degree of complexity of the software being used, the specific ICT-based tasks, and the types of ICT concepts to be taught, which might affect the pupils' learning. Soft ware tools have various degree of complexity. It is thus important to understand the software tool in terms of usability, functionality, detail richness, and design criteria before applying the ICT teaching method. Clearly, the degree of complexity of software tools could be a serious obstacle for applying the ICT teaching method (Herskin, 2004). Analysis of student teachers' project reports, discussions, and observations of their teaching activities showed that they experienced software tools in a variety of ways. It appears that the ICT teaching subject and the associated soft ware tool affected the way student teachers implemented the ICT teaching method, and how they interpreted the underlying principles and concepts of the software. This is in line with previous research that has shown that different types of soft ware will have different effects on pupils' learning(Cox \& Marshall, 2007). The opport unities provided by a range of soft ware could only be taken by pupils if the student teachers themselves know enough about the software to be able to design task-based activities, instruction sheets, situated examples, and visualizations of the underlying principles of the software. The teaching of a soft ware tool, e.g. Microsoft Access, will have limited effect if the student teacher has not understood the opport unities that the soft ware provides, such as the concepts and techniques of data representation and modeling, metaphors and capabilities of type of application. Clearly, without sufficient knowledge of the software being used, it could be difficult for student teachers to apply the ICT teaching method in all its dimensions.

\section{The new educational reform and digital literacy}

Digital literacy has become compulsory and should be integrated in all subjects, including ICT education. It is thus necessary to understand what "digital literacy" means and what it means to teach and do research on digital literacy. As described in the preceding sections, digital literacy means not only acquiring computing skills, but it entails a shift away from technologically-driven model of ICT teaching towards one based on innovative pedagogies and contemporary learning theories, as illustrated in this paper. This means an emphasis on developing and sharing pedagogic expertise concerning innovative ICT teaching methods both with school teachers and student teachers in collaboration with university teachers. Collaboration between universities and schools may encourage teachers to clarify the concept of digital literacy both from the theoretical and practical point of view. It would serve to elevate the role of student teachers in affect ing ICT pedagogy, enhance their motivation, and confidence in trying out new pedagogical methods.

\section{Limitations of the Study}

The present work was a study in which student teachers' application of a learner-centered ICT teaching method in two successive experiments in different secondary schools were studied. The number of experiments with the teaching method and the sample size (9 student teachers and 191 pupils of the first experiment and 3 student teachers and 50 pupils of the second experiment) may not be sufficient to adequately support the findings of this work. Hence, new cycles of experimentations and evaluations of the ICT teaching method in fut ure studies are warrant ed to generalize the findings of the present work. The author is in a process of finishing the third experiment with the ICT teaching method in collaboration with new student teachers. The evaluation results will be published in details in a new paper. In addition, the methods used for collect ing empirical data should be assesse $d$ and refined to ensure their quality, and eventually, completed with supplementary, both quant it at ive and qualitative methods, such as experimental and quasi- 
experimental design, to compare mean results to standardized tests between atreatment and a control group, as well as structured interviews and similar methods. More importantly, however, is to continue to study ICT teaching not as an isolated variable, but as an integrated process using a combination of qualitative and quant itative dat a collection methods. The author intends to gather new data in future experiments in order to confirm the findings of this work, as well as to obtain a more in-depth theoretical understanding of the process of introducing innovative ICT pedagogies in secondary schools.

\section{Conclusion}

The ICT teaching method presented in this paper has the potential to improve the pedagogy of ICT as a subject in upper secondary schools. The method is learner-centered as it takes into account the learner's needs and prerequisites. Even if it is impossible to draw any general conclusions from the experiments that were performed in 2005 and 2006, it can be ascertained that student teachers made a real progress in their attempt to apply the ICT teaching method in their classrooms. To exploit the full potential of the method in fut ure experiments requires the stakeholders involved in teacher education and secondary schools to be initiated into all its aspects. The implementation entails taking into consideration both internal and externals factors affecting the introduction of innovative ICT teaching methods, changing the stakeholders' views and practices to help them integrate innovative ICT pedagogies into secondary school environments. Pedagogical changes and innovations in the ICT subject in secondary schools can be achieved only through the iterative and cont inuous cycle of experimentations and evaluations in varied school contexts. The author intends to use the Design-based research paradigm to explore in future experiments the application of the ICT teaching method in more details and depth in order to gain theoretical and practical insights about the process of introducing innovative ICT teaching methods in upper secondary schools in compliance with the concept of digital literacy of the new educational reform in Norway.

\section{References}

Barab, S. \& Squire, K. (2004). Design-based research: Putting a stake in the ground. The Journal of the Learning Sciences, 13(1), 1-14.

Barak, M. (2006). Instructional principles for fostering learning with ICT: Teachers' perspectives as learners and instructors. Education and Information Technologies, 11, 121-135.

Beverly, B. F., \& Bronwen, C. (2002). Formative assessment and science education. London: Kluwer Acad emic.

Bitan-Frielander, N., Dreyfus, A., \& Milgrom, Z (2004). Types of "teachers in training": The reactions of primary school science teachers when con fronted with the task of implementing an innovation. Teacher and Teacher Education, 20, 607-619.

Brodahl, C., Fagernes, M., \& Hadjerrouit, S. (2007). Applying and evaluating understanding-oriented ICT user training in upper secondary education. Issues in Informing Science and In formation Technologies, 4, 473-490. Retrieved December 12, 2007 from http://proceedings.informingscience. org/InSITE2007/IISIT v4p473-490Brod287.pdf

Bruner, J. (1990). Acts of meaning. Cambridge, MA: Harvard University Press.

Bryman, A. (2004). Social research methods (2nd ed.). New York: Oxford University Press.

Cochran-Smith, M. (2005). Teacher educators as research ers: Multiple perspectives. Teacher and Teacher Education, 21, 219-225.

Cox, M. J., \& Marschall, G. (2007). Effects of ICT: Do we know what we should know? Education and Information Technologies, 12, 59-70. 
Dagdilelis, Satratzemi, \& Evangelidis (2004). Introducing secondary education students to algorithms and programming. Education and Information Technologies, 9(2), 159-173.

Dean ey, R., Ruthven, K., \& Hennessy, S. (2003). Pupil perspectives on the contribution of information and communication technology to teaching and learning in the secondary school. Research Papers in Education, 18(2), 141-165.

The Design-Based Research Collective (2003). Design-based research: An emerging paradigm for educational inquiry. Educational Research, 32 (1), 5-8.

Duffy, T. M., Lowyck, J., \& Jonassen, D. H. (1993). Designing environments for constructive learning. Berlin: Springer-Verlag.

Erstad, O. (2006). A new direction? Digital literacy, student participation and curriculum reform in Norway. Education and Information Technologies, 11, 415-429.

Gagne, E., Yekovich, C., \& Yekovisch, F. (1993). The cognitive psychology of school learning $\left(2^{\text {nd }}\right.$ ed.). New York: HarperCollins.

Hammond, M. (2004). The Peculiarities of teaching inform ation and communication technology as a subject: A study of trainee and new ICT teachers in secondary schools. Technology, Pedagogy and Education, 13(1), 29-42.

Hayes, D. N.A. (2007). ICT and learning: Lessons from Australian classrooms. Computers \& Education. 49, 385-395.

Hennessy, S., Ruthven, K., \& Brindley, S. (2005). Teacher perspectives on integrating ICT into subject teaching: Commitment, constraints, caution, and change. Journal of Curriculum Studies, 37(2), 155192.

Hsu, S. (2004). Using case discussion on the web to develop student teacher problem solving skills. Teacher and Teacher Education, 20, 681-692.

Herskin, B. (2004): IT-training - The user in the centre (in Danish. Original title: $\Pi$-undervisning - med brugeren i centrum). København: Nyt Teknisk Forlag.

Jedeskog, G., \& Nissen, J. (2004). ICT in the classroom: Is doing more important than knowing? Education and Information Technologies, 9(1), 37-45.

Karagiorgi, Y., \& Symeou, L. (2005). Translating constructivism into instructional design: Potential and limitations. Educational Technology \& Society, 8(1), 17-27.

Krumsvik, R. (2006). The digital challenges of school and teacher education in Norway: Some urgent questions and the search for answers. Education and Information Technologies, 11, 29-256.

Loughran, J., \& Berry, A. (2005). Modeling by teacher educators. Teacher and Teacher Education, 21, 193-203.

Lin, B., \& Hsieh, C. (2001). Web-based teaching and learner control: A research review. Computers \& Education, 37(3-4), 377-386.

McDougall, A., \& Boyle, M. (2004). Students' strategies for learning computer programming: Implications for pedagogy in informatics. Education and Information Technologies, 9(2), 109-116.

Mayes, J. T., \& Fowler, C. J. (1999). Learning technology and usability: A framework for understanding coursew are. Interacting with Computers, 11(5), 485-497.

Minaidi, A. \& Hlapanis, G. H. (2005). Pedagogical obstacles in teacher training in information and communication technology. Technology, Pedagogy and Education, 14(2), 241-254.

Niederhauser, D. S., \& Stoddart, T. (2001). Teachers' instructional perspectives and use of educational software. Teacher and Teacher Education, 17, 15-31.

Nordkvelle, Y. T., \& Olson, J. (2005). Visions for ICT, ethics and the practice of teachers. Education and Information Technologies, 10(1-2), 19-30. 
Hadjerrouit

Pearson, M., \& Naylor, S. (2006). Changing contexts: Teacher professional development and ICT pedagogy. Education and Information Technologies, 11, 283-291.

Piaget, J. (1971). Genetic epistemology. New York: W.W. Norton.

Plomp, T., Pelgrum, W.J. \& Law, N. (2007). SIT ES2006 - International comparative of pedagogical practices and ICT integration in education. Education and Information Technologies, 12, 83-92.

Postholm, M. B. (2006). The teacher's role when pupils work on task using ICT in project work. Educational Research, 48(2), 155-175.

Sein, M. K., Bostrom, R. P., \& Olfman, L. (1998). Re-conceptualizing IT training for the work force of the future. Proceedings of the Conference on Computer Personal Research (ACM SIGCPR), 233-241.

Steffe, L. P., \& Gale, J. (Eds.). (1995). Constructivism in education. New Jersey: Lawrence Erlbaum Associates.

UNESCO. (2002). Information and communication technology in education: A curriculum for schools and programme of teacher dev elopment. Retrieved January 19, 2008 from http://unesdoc.unesco.org/images/0012/001295/129538e.pdf

Valcke, M., Rots, I., Verbecke, M. \& van Braak, J. (2007). ICT teacher training: Evaluation of the curriculum and training approach in Flanders. Teaching and Teacher Education, 23(6), 795-808.

Volman, M. (2005). A variety of roles for a new type of educational technology and the teaching pro fession. Teaching and Teacher Education, 21, 15-31.

Vygotsky, L.S. (1978): Mind and society: The development of higher mental processes. Cambridge, MA: Harvard University Press.

Watson, D. (2006). Understanding the relationship between ICT and education means exploring innovation and change. Education and Information Technologies, 11, 199-216.

Webb, M. E. (2002). Pedagogical reasoning: Issues and solutions for the teaching and learning of ICT in secondary schools. Education and Information Technologies, 7(3), 237-255.

Wengler, E. (1998). Communities of practice: Learning, meaning, and identity. London: Pinter.

Woollard, J. (2005). The implication of the pedagogic metaphor for teacher education in computing. Technology, Pedagogy and Education, 14(2), 189-204.

Wu, C-C., Lee, G. C., \& Lai, H-K. (2004). Using concept maps to aid analysis of concept presentation in high school computer textbooks. Education and Information Technologies, 9(2), 185-197.

\section{Biography}

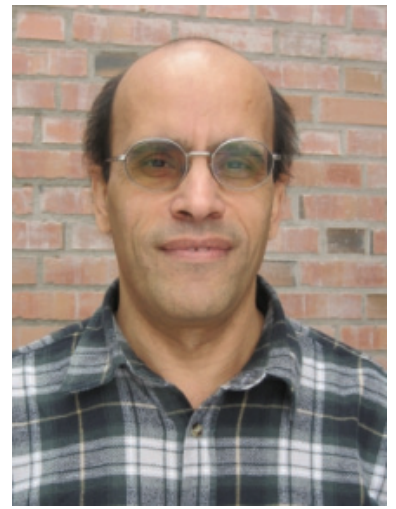

Said Hadje rrouit received the MS and $\mathrm{PhD}$ degrees in Software Engineering and Artificial Intelligence from the Technical University of Berlin (Germany), in 1985 and 1992, respectively. He joined University of Agder, Kristiansand (Norway) in 1991. He is currently an Associate Professor of Computer Science at the Faculty of Technology and Sciences. He has been in the teaching profession for 26 years. He has extensive experience in teaching object-oriented programming, Web engineering, soft ware development, databases, and didactics of ICT . His research interests include object-oriented software development, computer science and software engineering education, didactics of informatics, ICT in mathematics education, development of e-Learning systems. Hadjerrouit has published over 60 papers in international journals and conference proceedings. 